Energy Research Journal 2 (1): 6-16, 2011

ISSN 1949-0151

(C) 2011 Science Publications

\title{
Forecasting of Energy Consumption and Pollutant Emission for Road Transportation Policies Evaluation
}

\author{
${ }^{1}$ Punravee Kongboontiam and ${ }^{2}$ Rungsun Udomsri \\ ${ }^{1}$ Faculty of Architecture and Environmental Design, \\ Maejo University, Chiang Mai, 50290, Thailand \\ ${ }^{2}$ Department of Civil Engineering, Faculty of Engineering, \\ Chiang Mai University, Chiang Mai, 50200, Thailand
}

\begin{abstract}
Problem statement: The energy demand in Thailand has significantly increased over last ten years, particularly in transportation sector. Road transportation contributes the highest energy consumption, $38 \%$ of the total energy in the whole country, but it consumes $60 \%$ of the total energy usage in the northern region of Thailand. Various chemical pollutants emitted from the road transportation affecting to human health and global warming situations. Approach: This study applied the system dynamics model to forecast the energy consumption and pollutant emission from the road transportation and to evaluate the policies in transportation management. The model integrates five related systems: (1) the socio-economic, (2) demographic, (3) land use, (4) transportation and (5) energy consumption and pollutant emission of vehicle. Data from 2002-2009 was collected and used to forecast the system from 2010-2030. The proposed model was applied to evaluate and compare five transportation policy scenarios including road expansion, public transit incentive, land use restriction, alternative vehicle (eco-car) promoting and alternative fuel promoting. Results: The both energy consumption and pollutant emission in the study area will increase substantially if no management plans are implemented. The energy consumption will increase from 958.2 kTOE in 2010-1,144.8 and 1,369.2 kTOE in 2020 and 2030. The pollutant emission will increase from 2.983 million MTCOE in 2010-3.497 and 4.182 million MTCOE in 2020 and 2030. Among five proposed scenarios, the public transit incentive policy maximizes the goal of energy conservation. It can save $730.21 \mathrm{kTOE}$ and reduce 2.23 million MTCOE per year. Conclusion/Recommendation: The system dynamics modeling approach appropriates to simulate the trend of energy consumption and pollutant emission from the transportation sector. This application could be used as the tool for planning and management the transportation in context of the energy conservation and sustainably.
\end{abstract}

Key words: Energy consumption, pollutant emission, road transportation, system dynamics, transit incentive, northern region, system dynamics, energy consumption, public transit incentive, alternative vehicle, pollutant emission

\section{INTRODUCTION}

Energy plays an essential role in sustaining human activities in many sectors such as transportation, electrical generation, industrial and household sector. Inevitably, energy is a fundamental factor for national development of the nation (EPPO, 2006). The energy shortage has been the major issues in economic development in Thailand for many years. For example, in 2009, the total commercial energy in Thailand was consumed 82,345 kilotons of Oil Equivalent unit (kTOE), which approximately valued
48.5 billion USD EPPO 2009. However, the domestic energy resource can supply only $42 \%$ of the total demand. Therefore, Thailand must import 46,016 kTOE in 2009, which cost about 33.1 billion USD per year EPPO 2009. This is of course due to the fact that Thailand is still heavily dependent of imported oil. The statistics from 1999-2009 show that the energy demand in Thailand still increasing average $3.9 \%$ per year and the petroleum oil, a primary commercial energy and strongly influence of economic growth in Thailand, has been increasing about $1.7 \%$ with estimated national economic growth 3.0-5.0\%.

Corresponding Author: Punravee Kongboontiam, Faculty of Architecture and Environmental Design, Maejo University, 63, Nong Han, Sansai, Chiang Mai, 50290, Thailand Tel: +6653873360/ext. 113 Fax: +6653873367 
Transportation sector is one of the major energy consumers among the economic sectors of Thailand over the last ten years. It consumes $37 \%$ of the total energy consumption in the whole country, which values approximately 15.75 billion USD. In each year, Thailand spends more than 14.5 billion USD for oil fuel cost, approximately $14.3 \%$ of the Gross Domestic Product (GDP) or $12 \%$ of total freight import values DEDE 2009. In addition, road transportation has the highest contribution in energy consumption of the transportation sector. It consumes $96.7 \%$ of total energy consumption in the transportation sector DEDE 2009. Thus, it affects to rise up the fuel demand as the highest proportion. The prediction found that the road transportation will growing up from the ninth to tenth plan of the national economic and social development plan, which was higher than in rail and water transportation sectors (NESDB, 2002).

The growth of energy demand causes not only the national economy loss due to its shortage and high production costs, but also the air pollution from the vehicle's combustion engine process leading to human health and global warming problems. Such chemical pollutant emissions include Sulfur Dioxide $\left(\mathrm{SO}_{2}\right)$, Nitrogen Oxides $\left(\mathrm{NO}_{\mathrm{x}}\right)$, carbon monoxide $(\mathrm{CO})$, Hydrocarbon (HC) and particular matters less than 10 Micrometers $\left(\mathrm{PM}_{10}\right)$ that might pollute the atmosphere and adversely affect human health (Milt et al., 2009). The statistics from the Energy Planning And Policy Office (EPPO) revealed that pollution emitted from the road transportation sector has gradually increased by $51.7 \%$ million Metric Tons of the Carbon dioxide Equivalent unit (MTCOE) per year from 1997 onward EPPO 2010.

According to those reasons, the energy consumption especially in the transportation sector is the importance factor reflecting to the developing of the country and it needs to be managing. The Thai government by the ministry of energy has to oversee and generate policies and plans, as to make recommendations regarding energy measures and effectively satisfy energy needs of the country and leads to a sustainable energy (EPPO, 2006). In addition, the policies to apply for energy conservation and saving are formulated and implemented in Thailand. They hoped that when those plans are applied into practice, the energy would be used more efficiently and sustainably. However, the result from the different policies and measures are difference in the value of energy conservation and economic saving. Therefore, the appropriated policy for applying in this study area would be comparing and exploring the priorities to achieve the main target.
The forecasting of energy consumption and vehicle emission is complicated in nature, because the characteristics of transportation and energy demand are related to many attributes and change over time. Therefore, the objective of this study is to forecast the energy consumption in kTOE unit and pollutant emission represented by the MTCOE unit from the road transportation system in the regional area scale of Thailand. In addition, this study also evaluates the proposed policy scenarios that can be maximizes the energy conservation and minimizes the pollutant emission. The five different policy scenarios in transportation management were compared to be helpful reference for transportation planning and energy conservation strategy in the northern region of Thailand.

The study area: The study area as shown in Fig. 1 includes eight provinces in the northern region of Thailand: Chiang Mai, Chiang Rai, Lampang, Lamphun, Phayao, Phrae, Nan and Mae Hong Son. It covering $85,852 \mathrm{~km}^{2}$ with 5.8 million populations and more than one-half of the total population resides in Chiang Mai and Chiang Rai and it had tended to increase $0.13 \%$ per year or average in 7,362 persons per year. The Gross Regional Product value (GRP) of the study area was about 12,740 million USD and the average annual Gross Provincial Product (GPP) per capita is approximately 2,210 USD per person. Referred from the GPP statistic from 2001-2010, the average GPP growth was $8.1 \%$ per year. The number of the vehicle registered in the end of 2010 was 2.79 million vehicles which $66.2 \%$ were motorcycle. The vehicle population has been increasing average $6.8 \%$ per year. The fast growth of vehicle ownership has caused concerns over traffic congestion, energy demand, air pollution, health impact and livable of the region. The statistic data of the study area are summarized in Table 1.

Inside the transportation infrastructure in this study area, the total length of road network is around 46,588 kilometers. The statistical data obtained from the Department Of Highway (DOH) in the last ten years shows that the Annual Average Daily Traffic (AADT) on the primary intercity routes is about 8,496 vehicles per day. The AADT is varied based on the functional types of highway. It is up to 14,542 vehicles per day on the primary major routes (Route No. 1 and 11) and it is only 2,662 vehicles per day on the minor routes on the average. The average traffic volume in highway networks increases about $4.4 \%$ per year. Among different transportation mode, a motorcycle has the highest share in the study area. 
Energy Rec. J. 2 (1): 6-16, 2011

Table 1: General data of the northern region of Thailand

\begin{tabular}{|c|c|c|c|c|c|c|c|c|}
\hline $\begin{array}{l}\text { Province } \\
\text { unit }\end{array}$ & $\begin{array}{l}\text { Area } \\
\mathrm{km}^{2}\end{array}$ & $\begin{array}{l}\text { District } \\
\text { districts }\end{array}$ & $\begin{array}{l}\text { Population } \\
\text { persons }\end{array}$ & $\begin{array}{l}\text { GPP million } \\
\text { USD }\end{array}$ & $\begin{array}{l}\text { GPP per capita } \\
\text { USD }\end{array}$ & $\begin{array}{l}\text { Resisted vehicles } \\
\text { vehicles }\end{array}$ & $\begin{array}{l}\text { Road distance } \\
\mathrm{km}\end{array}$ & $\begin{array}{l}\text { Annual fuel } \\
\text { Sale kTOE }\end{array}$ \\
\hline Chiang rai & 11.678 & 180 & $1,248,530$ & 1,9740 & 1,645 & 536,6170 & 8,1650 & 168.906 \\
\hline Chiang mai & 20.107 & 240 & $1,668,562$ & 4,1600 & 2,616 & 989,6650 & 11,223 & 356.546 \\
\hline Nan & 11.472 & 150 & 476,1190 & 78300 & 1,607 & 180,0130 & 5,5250 & 50.8310 \\
\hline Phayao & 6.3350 & 900 & 487,4740 & 83100 & 1,564 & 214,8980 & 4,1780 & 51.5240 \\
\hline Phrae & 6.5390 & 800 & 462,1420 & 78200 & 1,518 & 216,4480 & 4,0520 & 58.5120 \\
\hline Mae Hong son & 12.681 & 700 & 251,7740 & 35600 & 1,550 & 42,67700 & 2,7290 & 22.7010 \\
\hline Lampang & 12.534 & 130 & 765,3710 & 1,5910 & 1,948 & 373,0670 & 6,7620 & 226.294 \\
\hline Lamphun & 4.5060 & 800 & 405,5320 & 2,2640 & 5,221 & 233,1540 & 3,9540 & 61.8640 \\
\hline Total & 85.852 & 102 & $5,765,504$ & 12,741 & 2,209 & $2,786,539$ & 46,588 & 997.178 \\
\hline
\end{tabular}

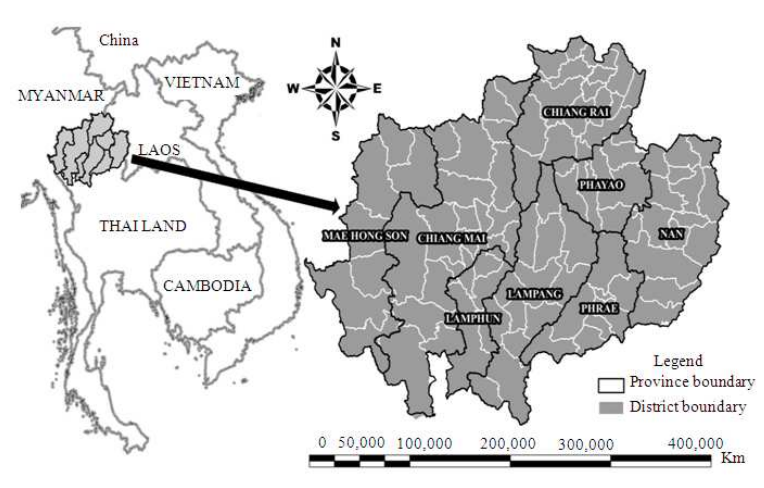

Fig. 1: The study area and zoning

It covers about $42.4 \%$ of the daily traffic volume is motorcycle, while passenger cars, pickups and public transits are about $30.9,15.5$ and $5.4 \%$, respectively.

\section{MATERIALS AND METHODS}

The forecasting of energy consumption and emission from the transportation sector is necessary to identify the various factors and model the relationships that not only focused in the transportation system but also related to other systems such as socio-economy, demography, land use, transportation, energy technology and environment. Because of the transportation system is a much complex system with multiple variables and feedback interrelations, it is not appropriate to use the ordinary approach to simulate and analyze the energy consumption and pollutant emission of the system. Therefore, the system dynamics modeling approach has been applied in this study to simulate and forecast the energy consumption and pollutant emission from the road transportation.

The system dynamics modeling, developed by Jay W. Forrester in 1960s, is a methodology to understand how complex systems change over time and how the system variables can interact with another in order to simulate their changes (Pfaffenbichler, 2003). It deals with internal feedback loops and time delays that affect the behavior of the entire system. It differs from other approaches in using feedback loops, stocks and flows, which help describe complex systems (Richmond, 2005). The advantages of the system dynamics model over the other forecasting models are the presence of the feedback loops, stocks and flows that help describe complex systems and allow updating the parameter values. In general, the system dynamics model is used to evaluate the performance of the system and analyze the relationship between related systems. It is applied in urban modeling, explaining the relationship between transportation and land use and estimating impacts of the system from the many policies, modeling the economic system.

This study propose the system dynamics model to represent the behavior of road transportation system in the upper northern region of Thailand and also to forecast the energy consumption and pollutant emission from the road transportation sector, in order to simulate the impacts from the alternative scenarios which can be appropriated for energy saving and environment conservative policy in Thailand. Therefore, this study adopted the ENTASIM model, developed by. For use as a modeling platform to simulate the road transportation system and estimate the energy consumption and pollutant emission. The ENTASIM model concept is based on the identification of variable values and interrelationship between five difference systems of socioeconomic, demographic of population, land use, road transportation and energy consumption and emission from the traveling vehicle, which the impacts of the last system would be feedback to make changes to the others in the next period of time. The concepts of each component are described as follow.

Socio-economic system: The Socio-Economic (SE) system represents the changes in the travel utility, which are influenced by social and economic variables for different modes of travel. The socio-economic variables considered in the SE system are average 
household size, average income per capita, vehicle sale prices and fuel prices.

The travel utility in this system includes the travel cost and travel time of each transportation mode, which leads to the calculation of the proportion of vehicle choices in the transportation system. The inputs of the SE system are these socio-economic variables in the current year, while the outputs are the travel utility of the current year and those socio-economic variables in the next year. The relationship used in the SE system is a linear mathematical equation. The model applies the growth rate technique to forecast the average income per capita, the average household size, fuel price and vehicle sale price in the next year. Further, the model estimates travel cost and travel time from the average rate of fuel consumption by transportation and average speed of travel, respectively.

Demographic system: The Demographic (DM) system represents the changes in the number of populations in the district area. It is influenced by birth, death and migration rates (migration-in and migration-out) (Demeny and McNicoil, 2003) caused by the economic system (Morand et al., 2010). The total population is used to estimate the number of workers, students and employers in each district area. The DM system describes the relationship among these demographic system variables. The relationship used in the DM system is also a linear mathematical equation. The model calculates the changes in the total number of population in the regional zones in each year. The number of students and workers in each zone are then calculated from the total number of population their growth rates. The demographic variables derived from the DM system affect the changes in the land use area in the geographic and land use system and the change in travel behavior in the transportation system in the next year.

Geographic and land use system: The Geographic and Land use (GL) system represents the change in total area of each land use type in the district areas (Prathumthip, 2002). The land use types in this study are classified into six types: (1) forest area, (2) agriculture and irrigation agriculture area, (3) urban and business area, (4) residential area, (5) government and public infrastructure area and (6) industrial and other area. The change in the size of each land use type is affected by population density derived from the demographic system, road density and average area travel speed derived from the transportation system. The outputs of this GL system affect the changes in travel behavior in the transportation system and the changes in population in the demographic system in the next year. The relationship used in the GL system is a multinomial logit regression model, which calculates the probability of the change in each land use patterns.

Transportation system: The Transportation (TT) system represents the travel demand, traveling behavior and vehicle activities within the district area (intrazonal) and between the districts (inter-zonal). The relationship model in the TT system is based on the conventional four-step transportation process (Ortuzar and Willumsen, 2011) comprising (1) trip generation process where generate a number of production trips from the original zone and attraction trips to the other zone, (2) trip distribution process which represents a direction and calculate a number of trips from the origin to destination as an origin-destination matrix, (3) modal split process which represents the proportion of transportation mode (vehicle type) used and (4) trip assignment process which calculates a number of vehicles in the transportation network (traffic volume) and estimates the traffic situation (average speed of the vehicle, traffic volume per road capacity or $\mathrm{V} / \mathrm{C}$, travel time and delay). The outputs of this system affect the energy consumption and pollutant emission and feedback to make the land use changes in the next year. The relationships used in the TT system are described as follows.

Trip generation is formulated in a linear mathematical equation. This model calculates the number of trip production and trip attraction separated by four trip purposes including work trip, school trip, other trip and comeback home trip.

Trip distribution is formulated in a gravity model method. The gravity model uses friction factor to distribute travel demands to their destination zones based on the distance between original and destination. The model calculates the number of trips that travel between origin and destination zones, as a result, an Origin and Destination (O-D) matrix is created.

Modal split or vehicle choice is formulated in a multinomial logit regression method to calculate the proportion of vehicle being chosen and the proportion of mode shifted from the previous mode to the preferred mode. The vehicle models are typically classified into three main categories: Motorcycle (MC), gasoline engine vehicle (PC) and diesel engine vehicle (PU). For PC mode, vehicles are divided into four types based on the engine size: less than $1200 \mathrm{cc}$. (PC2), 1200-1500 cc. (PC3), 1500-2000 cc. (PC4) and greater than $2000 \mathrm{cc}$. (PC5). For PU mode, vehicles are divided into 3 types based on the engine size: less than $2500 \mathrm{cc}$. 
(PU6), 2500-3000 cc. (PU7) and greater than $3000 \mathrm{cc}$. (PU8). In addition, the vehicle choices for intercity transportation are all the passenger modes, intercity bus (BUS), small truck (T4T6), middle truck (T10) and large truck (T18AT).

Trip assignment is formulated by all-or-nothing assignment method based on shortest distance calculated from the spatial analysis in GIS application. The first part is the model to calculate the total distance of Vehicle Traveling (VKT), which includes both intrazonal and inter-zonal trips. The second part is the model to calculate the average area speed, which represents the traffic situation in each zone. The model uses free flow speed and Volume per Capacity (V/C) as input variables to develop the speed-density relationship.

Energy consumption and emission of vehicle: The energy consumption and Emission from Vehicle (EE) system represents the total energy consumption and pollution emitted from vehicle uses. The energy consumption of each vehicle type is calculated from vehicle kilometer of travel and average speed and the total energy consumption is calculated by the sum of the product of energy consumption of each vehicle type and its fuel type (gasoline, gasohol E10, diesel, biodiesel B5 and Natural Gas for Vehicle or NGV). The tailpipe pollution emitted from the vehicles $(\mathrm{HC}, \mathrm{CO}$, $\mathrm{NO}_{\mathrm{x}}, \mathrm{SO}_{2}$ and $\mathrm{PM}_{10}$ ) are calculated from the total fuel consumption separated by type of fuel and finally, the pollution emitted are converted to the total tons of carbon dioxide equivalent. The outputs of this system feed back to the transportation system and socioeconomic system in the next year. Therefore, the EE system shows the situation of the energy consumption and emission by transportation in the study area. The relationship of the EE system is applied from the HDM4 model (Bennett, 2003) and calibrated by the vehicle testing data in the study area. The EE system uses a polynomial regression equation to calculate the total fuel consumption, which can be derived from vehicle types and the average area speed obtained from the TT system and uses a linear regression equation to calculate the total emission from fuel consumed by transportation systems (Bowyer et al., 1985).

Model formulation and forecasting process: The energy consumption and pollutant emission from the road transportation is primarily due to the people needs to travel for making activities at any destinations by various vehicle modes. It is necessary to integrate the related factors of this system comprising five related sectors, socio-economic, demographic and population, geographic and land use, transportation and energy consumption and pollutant emission of vehicle. According to the ENTASIM modeling platform, the model used for forecasting in this study formulated a causal and relationship diagram in order to understand the relationships among the various influence factors in the road transportation system of the study area as shown in Fig. 2. Consequently, the model mechanism and forecasting process should be considered and generated in a pattern of the period of time (yearly) as shown in Fig. 3. Then, the formulated model requires various parameters for input as the initial stage of the simulation model as shown in Table 2. The input parameters were collected from the reports and database during 2002-2009 of the National Statistical Office (NSO), the Provincial Operation Center (POC), the Land Development Department (LDD), the Office of transport and Traffic Policy and planning (OTP), the Department Of Highway (DOH) and the Energy Policy and Planning Office (EPPO). Furthermore, the vehicle fuel consumption data was collected from the vehicle-running test in Chiang Mai urban area in 2009 and the vehicle pollutant emission was collected from by the privately operated system of inspection stations under the land transport act and motor vehicle act. Finally, the model has forecasted the energy consumption in unit of Kilotons of Oil Equivalent (kTOE) and pollutant emission in unit of Matrix Tons Of Carbon Dioxide Equivalent (MTCOE) from the road transportation system of the study area during 2010-2030.

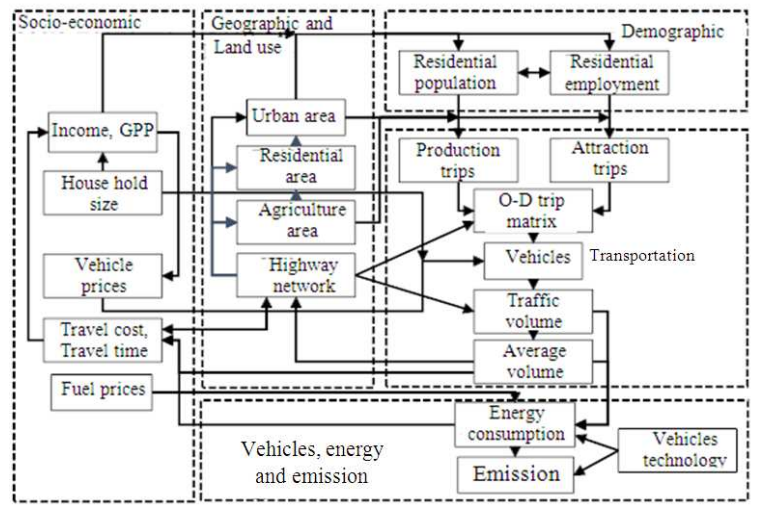

Fig. 2: Overall causal and relationship diagram of the energy and emission in the road transportation system 
Energy Rec. J. 2 (1): 6-16, 2011

Table 2: Summary of parameters for forecasting model

\begin{tabular}{|c|c|c|}
\hline Module & Input variables & Output variables \\
\hline $\begin{array}{l}\text { Socio-economic } \\
\text {. }\end{array}$ & $\begin{array}{l}\text { Income (Thai baht/month) travel cost (Thai baht) } \\
\text { GPP growth rate }(\%) \text { travel time (min.) } \\
\text { Household size (persons/house) } \\
\text { Fuel price (Thai baht/liter) } \\
\text { Vehicle price (million Thai baht/vehicle) }\end{array}$ & \\
\hline Demographic and population & $\begin{array}{l}\text { Birth rate (persons per } 1000 \text { population) } \\
\text { Dead rate (persons per } 1000 \text { population) } \\
\text { Migration rate (persons per } 1000 \text { population) }\end{array}$ & $\begin{array}{l}\text { The number of population, worker, student, } \\
\text { School size employment (persons) }\end{array}$ \\
\hline Geographic and land use & $\begin{array}{l}\text { Road density }\left(\mathrm{km} \mathrm{km}^{-2}\right) \\
\text { Population density }(\text { persons km} \\
\text { Average area speed }\left(\mathrm{km} \mathrm{h}^{-1}\right)\end{array}$ & $\begin{array}{l}\text { Urban and business area }\left(\mathrm{km}^{2}\right) \\
\text { Residential area }\left(\mathrm{km}^{2}\right) \\
\text { Public infrastructure area }\left(\mathrm{km}^{2}\right) \\
\text { Industrial and other area }\left(\mathrm{km}^{2}\right) \\
\text { Agriculture area }\left(\mathrm{km}^{2}\right) \\
\text { Forest area }\left(\mathrm{km}^{2}\right)\end{array}$ \\
\hline Transportation & $\begin{array}{l}\text { Population, } \mathrm{LU} \text { area }\left(\mathrm{km}^{2}\right) \\
\text { Distance matrix }(\mathrm{km}) \\
\text { Vehicle price }(\text { million Thai baht/vehicle) } \\
\text { Travel cost (Thai baht) } \\
\text { Travel time }(\mathrm{min} .) \\
\text { Free flow speed }(\mathrm{km} / \mathrm{h}) \\
\text { Road capacity }(\mathrm{PCU} / \mathrm{h}) \\
\text { Speed-density curve }\end{array}$ & $\begin{array}{l}\text { Production trips (persons-trips/day) } \\
\text { Attraction trips (persons-trips/day) } \\
\text { Trips O-D matrixes (persons-trips/day) } \\
\text { Proportion of vehicle modes }(\%) \\
\text { Vehicle kilometer travel or VKT (km/day) } \\
\text { Average area speed }(\mathrm{km} / \mathrm{hr} \text { ) } \\
\text { Traffic volume per road capacity }(\mathrm{V} / \mathrm{C})\end{array}$ \\
\hline Energy and emission of vehicle & $\begin{array}{l}\text { vehicle kilometer travel or VKT }(\mathrm{km} / \text { day }) \\
\text { Average area speed }\left(\mathrm{km} \mathrm{h}^{-1}\right) \\
\text { Consumption curve of each vehicle type } \\
\text { Emission factors of each fuel type and vehicle type }\end{array}$ & $\begin{array}{l}\text { Total energy consumption (kTOE/year) } \\
\text { Total pollutant emission (MTCOE/year) }\end{array}$ \\
\hline
\end{tabular}

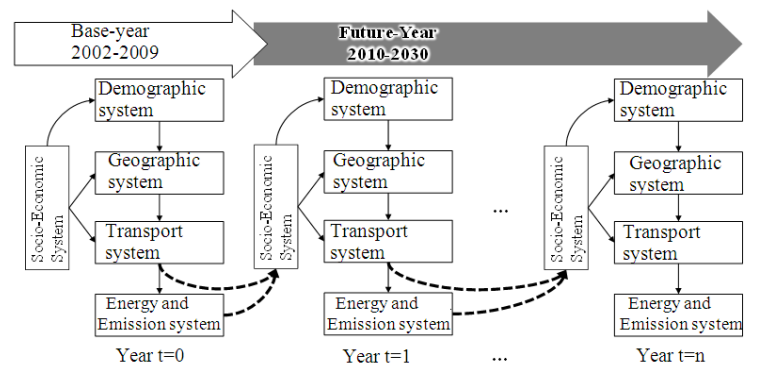

Fig. 3: Mechanism and time step of the energy and emission in the road transportation system

According to the model fitting are important issues in the model formulation and setup, this study confirm these issues wherewith validating the traffic volume output from the TT system with the historical data based on the method suggested by (Ortuzar and Willumsen, 2011). In addition, the annual energy consumption outputs from the model are compared with the fuel sales statistics between 2002-2009.

\section{RESULTS}

To demonstrate the model, this study applied the model to forecast the transportation demand, energy consumption and pollutant emission from the road transportation in the northern region of Thailand in the future year. In this case, the system was simulated under the most likely circumstance with minimum implementation, called the do-minimum scenario. In addition, this model was used to simulate the effects of appropriated policies and measures on transportation planning and management in enhancing energy conservation. According to the national policy in energy conservation by the EPPO and OTP, the potential strategies that can be applied in this study area was generated into five scenarios comprising (1) road expansion and improvement, (2) public transit incentives, (3) land use restriction, (4) alternative vehicle (eco-car) promoting and (5) alternative fuel promoting.

Do-minimum scenario forecasting: As mentioned above, it was applied to forecast the total annual energy consumed by vehicles in the study area from 2010 to 2030 based on assumption do-minimum scenario used as a reference. The results found that the travel demand in the study area increasing from 13.739 million person-trips per day in 2010 to 15.654 and 17.655 million person-trips per day in 2020 and 2030, respectively. It will be consuming the annual energy in the road transportation sector about $958.2 \mathrm{kTOE}$ in 2010 and increase to $1,144.8$ and 1,369.2 kTOE in 2020 and 2030, respectively, which the annual growth rate of $1.70 \%$ as shown in Fig. 4. 
Energy Rec. J. 2 (1): 6-16, 2011

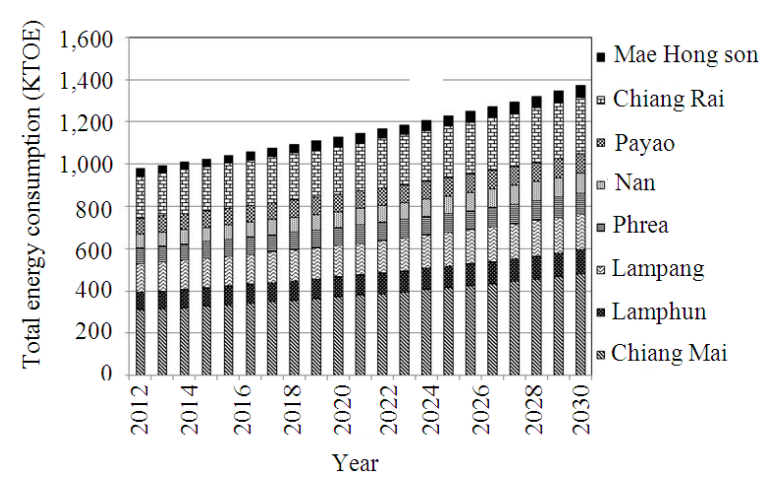

Fig. 4:Forecasting of annual energy consumption in the road transportation based on do-minimum scenario

According to the result from the energy consumption, the pollutant emitted from the road transportation contributed 2.983 million MTCOE in 2010 and continuously increasing to 3.497 and 4.182 million MTCOE in 2020 and 2030, respectively, which the same growth rate with energy consumption as shown in Fig. 5. Finally, the simulation results from this scenario were compared with the historical data observed during 2002-2009 for validating the model. The comparison reveals that the forecasted energy consumption has a difference from the fuel selling statistics by province from the EPPO in average 5.9\% which valued maximum difference $60.4 \mathrm{kTOE}$ as shown in Fig. 6.

Road expansion scenario forecasting: This policy scenario is initiated by the highway infrastructure improvement projects of the regional transportation development master plan by The DOH. In the study area, these two expressway construction projects in the upper northern region, which as part of the national expressway no. 5, are proposed and now these projects are in the end of the feasibility design phase. The projects will be planned to build in 2012 and finish in 2015. This policy scenario assumes that the two new expressway corridors will be implemented in 2015 . They are (1) the 6-lane expressway, 99-km connecting Chiang Mai-Lanphun-Lanpang and (2) the 6-lane expressway, $151-\mathrm{km}$ connecting Chiang Mai-Chiang Rai. The result from the forecasting shows that the annual energy consumption increasing from to $1,161.6$ and 1,402.2 kTOE in 2020 and 2030, respectively, which the annual growth rate of $1.83 \%$. It will be generating pollutant emission 3.55 and 4.28 million MTCOE in 2020 and 2030, respectively. This trend is higher consumption and emission than the dominimum scenario.

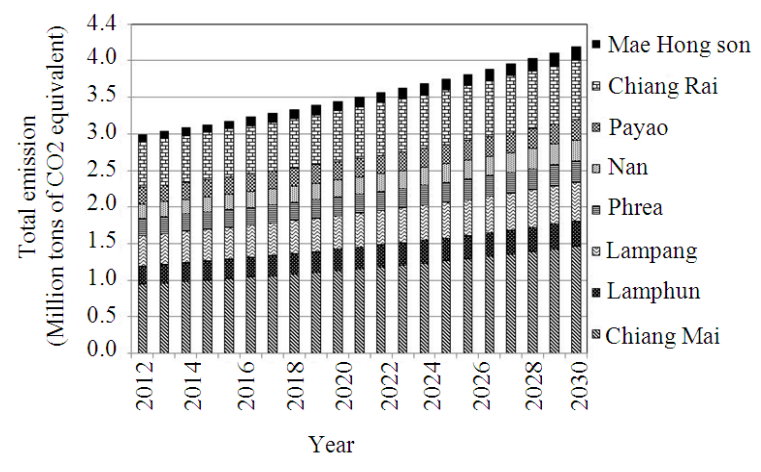

Fig. 5: Forecasting of annual pollutant emission from the road transportation based on

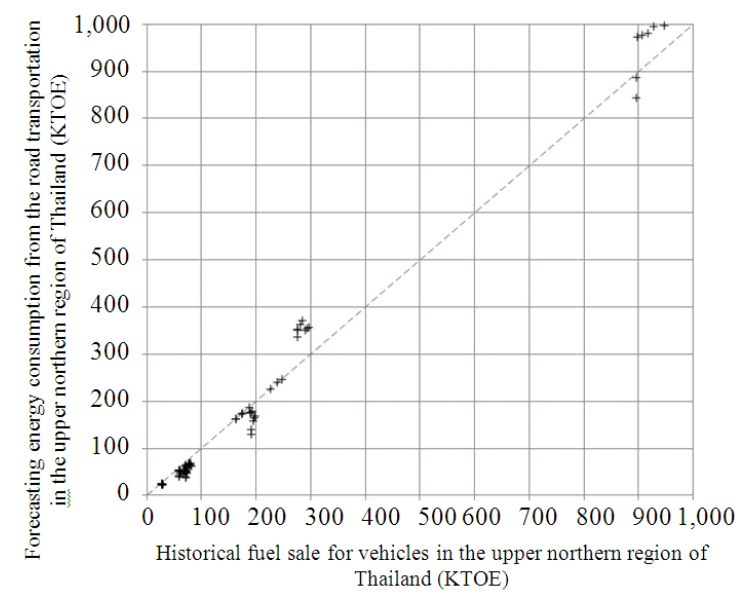

Fig. 6: Comparison of forecasted energy consumption with historical fuel selling based on do-minimum scenario

Public transit incentives scenario forecasting: This policy scenario is initiated by the motivation and needs of the public transit systems in the study area. Many researches show that public transit vehicles consume much less fuel per person than individual private cars. This policy scenario assumes the public transit systems are operated in the urban areas of the eight capital districts in the study area. The public transit systems in each capital district services in both primary routes (main routes) and secondary routes (feeder routes). The transit fare is assumed to be a half in average of the private vehicle operating costs. This scenario also assumes that the operation service distance of the transit system in each capital district is about $100 \mathrm{~km}$ (roundtrip) and the level of accessibility to the system is about $60 \%$. The result from the forecasting shows that the annual energy consumption increasing from to $1,108.2$ and 1,317.9 kTOE in 2020 and 2030, respectively, 
which the annual growth rate of $1.52 \%$. It will be generating pollutant emission 3.39 and 4.03 million MTCOE in 2020 and 2030, respectively. This trend is lower consumption and emission than the dominimum scenario.

Land use restriction scenario forecasting: This policy scenario is initiated from the road infrastructure development and expansion with on limitations, which lacking of planning and management in land use control. Because the highway expansion increases mobility of travel and accessibility to land use, then it feedback to attract more travel demand in the study area, which leads to the increase in the number of vehicle and energy usage. According to the land use data of the current year, the average road density in the study area is less than $1.0 \mathrm{~km}$ lane per $\mathrm{km}^{2}$ but there are many districts, especially the capital district of the provinces, where the road density will be rise to $2.0 \mathrm{~km}$ lane per $\mathrm{km}^{2}$. If there is no restriction of road expansion in the area, most land use will be less efficient since it will be allocated to roadways and travel demand will significantly increase. Therefore, this policy scenario assumes that land use restriction is proposed to implement in the districts where has the road density greater than $2.0 \mathrm{~km}$-lane per $\mathrm{km}^{2}$. The result from the forecasting shows that the annual energy consumption increasing from to $1,115.9$ and $1,313.9 \mathrm{kTOE}$ in 2020 and 2030, respectively, which the annual growth rate of $1.52 \%$. It will be generating pollutant emission 3.41 and 4.01 million MTCOE in 2020 and 2030, respectively. This trend is lower consumption and emission than the do-minimum scenario.

Alternative vehicle (eco-car) promoting scenario forecasting: This policy scenario is initiated from the increasing trend of eco-car usage and the number of eco-car development by the manufacturing. The eco-car is a small-sized vehicle with the engine size less than $1,500 \mathrm{cc}$. and the fuel consumption rate less than 20 $\mathrm{km} / \mathrm{l}$, which under the standard of United Nations Economic Commission for Europe (UNECE). Therefore, the eco-car policy is used to promote as a choice for the private mode that consuming low energy and low pollutant emission. Presently, this alternative vehicle has become very attractive for both of personal and governmental view, because it can be archived the goal of energy conservation in the private transportation. Moreover, the government has recently proposed a plan to reduce the vehicle tax for those vehicles with the small engine. This policy scenario assumes that the sale prices of passenger cars smaller than $1,200 \mathrm{cc}$. and that of pickup smaller than 2,500 cc. will decrease 100,000 Thai baht (approximately 3,225 USD) per vehicle since 2011 and reduces the registering tax of the eco-car average 5,000 Thai baht (approximately 160 USD) per vehicle in every next year. The result from the forecasting shows that the annual energy consumption increasing from to $1,116.5$ and 1,322.0 kTOE in 2020 and 2030, respectively, which the annual growth rate of $1.52 \%$. It will be generating pollutant emission 3.41 and 4.04 million MTCOE in 2020 and 2030, respectively. This trend is lower consumption and emission than the dominimum scenario.

Alternative fuel promoting scenario forecasting: This policy scenario is initiated from the introduction of renewable and alternate fuels in Thailand. This substitution reduces the dependency of oil petroleum, which mostly is imported from abroad. In present, there are several alternate fuels for vehicle. The famous type is Gasohol, which combines gasoline with ethanol at different proportions, for example, Gasohol E10, Gasohol E20 and Gasohol E85. The second type is Biodiesel, which replaces diesel with used organic oil at different proportions, for example, Biodiesel B5 and Biodiesel B10. The last type is the Compressed Natural Gas (CNG), which is generally known as NGV (natural gas for vehicle) in Thailand. This policy scenario assumes that the sale prices of these alternate fuels are decreased in order to attract more travelers to use less petroleum-dependent vehicles and as a result reduce emission pollution. This policy scenario will increase the difference of sale price between gasoline and gasohol in average 1.00 Thai baht (0.03 USD) per liter in every year. Further, this policy scenario will fix the sale price of NGV at 10.50 Thai baht (0.34 USD) per kilogram until 2015 and rise to 15.50 Thai baht $(0.50$ USD) per kilogram until 2020 and later set at the half price of diesel's sale price. The result from the forecasting shows that the annual energy consumption increasing from to $1,144.8$ and $1,369.2 \mathrm{kTOE}$ in 2020 and 2030, respectively, which the annual growth rate of $1.52 \%$. It will be generating pollutant emission 3.33 and 3.98 million MTCOE in 2020 and 2030, respectively. This trend is lower consumption and emission than the do-minimum scenario.

\section{DISCUSSION}

The forecasting based on the do-minimum scenario shows that the total distance traveled of vehicle in the 
study area is 48.18 million $\mathrm{km} \mathrm{day}^{-1}$ in 2010 and increases to 55.42 and 63.8 million $\mathrm{km} \mathrm{day}^{-1}$ in 2020 and 2030, respectively. These rapid increases will significantly affect the traffic situation in the highway networks in the study area. The average travel speed reduces from $58.9 \mathrm{~km} \mathrm{~h}^{-1}$ in 2010 to 55.0 and $50.9 \mathrm{~km}$ $\mathrm{h}^{-1}$ in 2020 and 2030, respectively. The traffic volume per road capacity ratio $(\mathrm{V} / \mathrm{C})$ increases from 0.32 in 2010 to 0.37 and 0.43 in 2020 and 2030, respectively. Compared among eight provinces in the study area, Chiang Mai province has the highest contribution in vehicle energy consumption and vehicle emission. It is approximately $33.2 \%$ share of the northern region of Thailand, followed by Chiang Rai (20.1\%), Lampang (13.2\%), Lamphun (8.2\%), Phrae (7.4\%), Phayao (7.2\%), Nan (6.8\%) and Mae Hong Son (3.8\%). Consider to the economic impacts of the study area, the energy consumption costs approximate 1.02 billion USD in 2010 and increases to 1.83 and 2.90 million USD in 2020 and 2030, respectively, which these estimates are based on the estimated fuel cost in the target years.

According to the scenario simulation, the appropriated policies applied in this study can classified into two policy groups. One is the investment policy that has a high capital cost, it comprising the road expansion and improvement and public transit incentives scenario. The other hand is the management and incentive policy that has a low capital cost and operating cost, it comprising the land use restriction, alternative vehicle (eco-car) promoting and alternative fuel promoting scenario. Then, the results of these five case scenarios were compared with the do-minimum scenario as a base case. In summary of the overall result as shown in Fig. 7 and 8, the public transit incentive scenario is the best alternative that maximally meets the goal of energy conservation, followed by the land use restriction, the eco-car promoting and the alternative fuel promoting scenario. Although the road expansion scenario that proposed to construct the new expressway can improve the consumption efficiency of the vehicle, in the other hand, this policy induces to increase the travel demand and vehicle usage, which affecting to increase the overall energy consumption and emission. It should be noted that the road expansion scenario has negative impact on energy conservation but this policy is essential to facilitate the economic and regional development, especially in the developing countries as Thailand. The comparison of the appropriated policy scenarios with the do-minimum scenario are summarized in Table 3.

Table 3: Average annual saving of policy scenarios compared with the do-minimum scenario

\begin{tabular}{|c|c|c|c|c|c|}
\hline $\begin{array}{l}\text { Performance } \\
\text { variables }\end{array}$ & $\begin{array}{l}\text { Road } \\
\text { expansion }\end{array}$ & $\begin{array}{l}\text { Public transit } \\
\text { promoting }\end{array}$ & $\begin{array}{l}\text { Land use } \\
\text { restriction }\end{array}$ & $\begin{array}{l}\text { Eco-car } \\
\text { promoting }\end{array}$ & $\begin{array}{l}\text { Alternative } \\
\text { fuel promoting }\end{array}$ \\
\hline $\begin{array}{l}\text { Total vehicle kilometer } \\
\text { of travel saving }(\mathrm{km})\end{array}$ & $-13,793,702$ & $113,399,748$ & $23,874,062$ & $16,904,033$ & 0.000 \\
\hline $\begin{array}{l}\text { Average travel speed } \\
\text { increasing }(\mathrm{km} / \mathrm{h})\end{array}$ & -0.370 & 3.660 & 0.650 & 0.45 & 0.000 \\
\hline $\mathrm{V} / \mathrm{C}$ reducing & -0.005 & -0.007 & 0.009 & 0.007 & 0.000 \\
\hline Total energy saving (kTOE) & -363.770 & 730.210 & 618.820 & 592.400 & 0.000 \\
\hline $\begin{array}{l}\text { Total pollutant saving } \\
\text { (million MTCOE) }\end{array}$ & -1.110 & 2.230 & 1.890 & 1.810 & 3.360 \\
\hline $\begin{array}{l}\text { Total travel cost saving } \\
\text { million USD/year) }\end{array}$ & -639.280 & $2,191.330$ & $1,085.440$ & 970.910 & $2,961.540$ \\
\hline
\end{tabular}

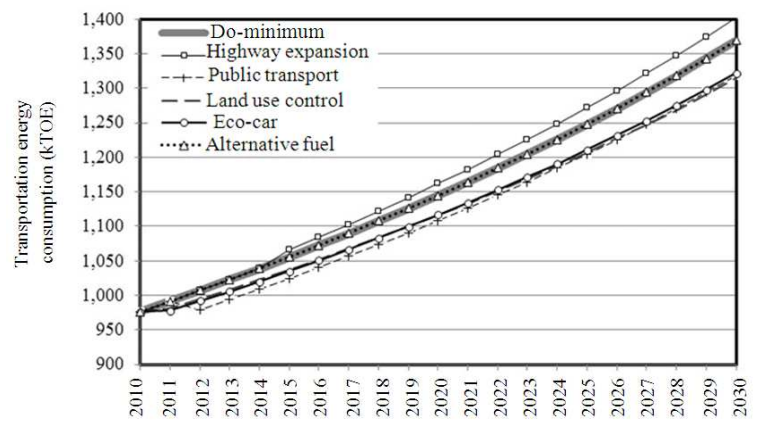

Fig. 7: Scenario comparison of annual energy consumption forecasting from the road transportation

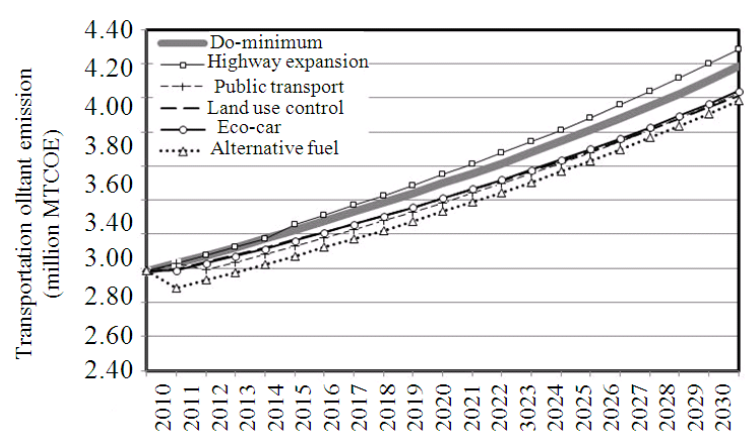

Fig. 8: Scenario comparison of annual pollutant emission forecasting from the road transportation 


\section{CONCULSION}

This study has developed the system dynamics model based on the ENTASIM modeling platform to forecasting the energy consumption and pollutant emission from the road transportation in the northern region of Thailand. According to the results, there are numerous factors that significantly affecting the energy consumption and pollutant emission from the road transportation systems. These relationships and factors are formulated into five related systems, including socio-economic system, demographic system, geographic and land use system, transportation system and energy and emission of vehicle systems.

The forecasting during 2010-2030 based on the dominimum scenario as the most likely case shows that the travel demand in the study area generated 13, 739, 321 person-trips per day in 2010 with average growth rate $1.23 \%$ per year. They desire to travel 48.18 million kilometers of vehicle travelling per day in 2010 and increases to 55.42 and 63.8 million kilometers per day in 2020 and 2030, respectively. These rapid increases will significantly affect the traffic situation in the highway networks in the study area. The average travel speed reduces from $58.9 \mathrm{~km} \mathrm{~h}^{-1}$ in 2010-55.0 and 50.9 $\mathrm{km} \mathrm{h}^{-1}$ in 2020 and 2030, respectively. The traffic volume per road capacity ratio (V/C) increases from 0.32 in 2010 to 0.37 and 0.43 in 2020 and 2030, respectively. The forecasting reveal that the road transportation consume 958.2 kTOE in 2010 and increase to $1,144.8$ and 1,369.2 kTOE in 2020 and 2030, respectively, which the annual growth rate of $1.70 \%$. The pollutant emitted from the road transportation contributed 2.983 MTCOE million in 2010 and continuously increasing to 3.497 and 4.182 million MTCOE in 2020 and 2030, respectively, which the same growth rate with energy consumption.

The application of this model to simulate the policy scenarios in the study area shows that the best policy that maximizes the goal of energy conservation is the public transit incentive in the capital districts of all provinces that have the transit fare equal to the half of vehicle operating costs. The land use restriction policy by control the road density do not exceed than $2 \mathrm{~km}$ lane per $\mathrm{km}^{2}$ can reduce the energy consumption in average $2.57 \%$ in short-term (less than 10 years) and 4.03 in long-term (10-20 years). The eco-car promoting policy can reduce the energy consumption in average $2.49 \%$. The fuel alternative policy that promoting the gasohol, biodiesel and NGV cannot reduce the energy consumption but it can decrease the import of petroleum oil average 105.6 kTOE per year. Although the road expansion policy would induce more travel demand and energy consumption but it also essentials for the development of Thailand. For the future study, we recommend to combine those policies or integrate with other appropriated strategies for simulation the situation of the regional area of Thailand. It could be used to find a better plan which can achieve the target of energy and environmental conservation.

The system dynamics model as the ENTASIM modeling platform is further recommended to simulate and forecast the energy consumption, pollutant emission and transportation situation in other region. This approach is potential forecasting because the system dynamics model appropriate to simulate the complex system with many interrelationships and it is easy to simulate the scenarios by changing the sets of input data, which are already available in the common databases in the other region of Thailand. This may be applicable in the Geographic Information System (GIS) for enhancing the ability of data analysis and reporting results. It helps to integrating, manipulating, spatial analysis and transportation information which useful for transportation and energy planning in the future application.

\section{ACKNOWLEDGMENT}

The study acknowledge to the National Statistical Office (NSO), the Provincial Operation Center (POC), the Land Development Department (LDD), the Office of transport and Traffic Policy And Planning (OTP), the Department Of Highway (DOH) and the Energy Policy and Planning Office (EPPO) for supporting all data. In addition, the authors would like to thank the department of mechanical engineering, faculty of engineering, Chiang Mai university for the academic support.

\section{REFERENCES}

Bowyer, D.P., R. Akcelik and D.C. Biggs, 1985. Guide to Fuel Consumption Analyses for Urban Traffic Management. 1st Edn., Australian Road Research Board, Vermont South, Victoria, Australia, ISBN: 9780869102206, pp: 98.

Bennett, C.R., 2003. Modeling Road User and Environmental Effects in HDM-4. HTC Infrastructure Management Ltd., Auckland, New Zealand.

Demeny, P.G. and G. McNicoil, 2003. Encyclopedia of Population. 1st Edn., Macmillan Publishers Ltd, USA., ISBN: 9780028656793, pp: 1040.

EPPO, 2006. Energy Policy and Planning Office. Ministry of Energy, Bangkok, Thailand. 
Milt, A., A. Milano, S. Garivait and R. Kamens, 2009. Effects of $10 \%$ biofuel substitution on ground level ozone formation in Bangkok, Thailand. Atmos. Environ., 37: 5962-5970. DOI: 10.1016/j.atmosenv.2009.07.062

Morand, E., L. Toulemon, S. Pennec, R. Baggio and F. Billari, 2010. Demographic modeling: The state of the art. Sustain City, Ined, Paris, France.

NESDB, 2002. The Tenth National Economic and Social Development Plan. National Economic and Social Development Board Office of the Prime Minister Bangkok, Thailand.

Ortuzar, J.D.D. and L.G. Willumsen, 2011. Modeling Transport. 4th Edn., John Wiley and Sons Ltd., Baffins Lane, Chichester, West Sussex, England, ISBN-10: 0470760397, pp: 606.
Pfaffenbichler, P., 2003. The Strategic, Dynamic and Integrated Urban Land use and Transport Model Metropolitan Activity Relocation Simulator (MARS): Development, Testing and Application. Vienna University of Technology, Vienna, Austria, pp: 277.

Prathumthip, M., 2002. Interaction modeling of transportation and land use in Chiang Mai City. Chiang Mai University.

Richmond, B., 2005. An Introduction to System Thinking. ISEE system, Inc., Lebanon, USA. 